\title{
Cost analysis of dexmedetomidine versus propofol during the implantation of a neurostimulator
}

To the Editor,

Recently, we published a study entitled: "Dexmedetomidine vs propofol as sedation for implantation of neurostimulators: A single-center single-blinded randomized controlled trial" in the Acta Anaesthesiologica Scandinavica. ${ }^{1}$

This randomized controlled trial compared dexmedetomidine with propofol during the implantation of a neurostimulator. ${ }^{2-4}$ During the lead implantation of most spinal cord neurostimulators, the patient has to be comfortable and without pain. However, the patient is expected to provide feedback during electrical mapping. Titrating sedatives and analgesics for this double goal can be challenging. Dexmedetomidine sedation resulted in higher patient satisfaction and allowed for better arousable sedation than sedation with propofol. Differences in hemodynamic parameters were found between the groups, but not regarded as clinically relevant.

This recent analysis is an addition to the above mentioned study.

There were three motives to study the financial impact of dexmedetomidine vs propofol during the implantation of a neurostimulator.

First, notwithstanding the results of our abovementioned study, several anesthesiologists in our center did not consider the use of dexmedetomidine during the implantation of a neurostimulator. As dexmedetomidine has only recently been approved-in 2018-for sedation analgesia by the European Medicines Agency (EMA), they assumed the use of dexmedetomidine to be more expensive than that of propofol.

Second, a European economic evaluation of the use of dexmedetomidine in intensive care units showed unexpectedly that dexmedetomidine sedation was more cost-effective than the standard sedatives propofol and midazolam. ${ }^{4}$ This, despite the long required duration of administration compared to that in the implantation of a neurostimulator. ${ }^{5}$

Third, although the costs of a procedure are important in themselves, the quality of the health care from the perspective of the patient, is increasingly seen as important. Considering this view and the results of our previous study, that is, the higher patient satisfaction and the allowance for better arousable sedation using dexmedetomidine compared to propofol, would justify a potential higher cost to a certain extent and was an additional reason to perform this analysis.

The cost analysis was conducted from the hospital perspective in 2018. The included costs associated with the procedure were those of the sedative agents, the other medications and the neurostimulation procedure. Costs were measured during the period between the start of the procedure and the patient's discharge from the recovery room.

The costs of the use of dexmedetomidine were significantly higher than the costs of the use of propofol (see Table 1). The results of sensitivity analysis were found to be consistent with this finding, with the exception of the original variant of propofol.

TAB LE 1 Results of the base case analysis and sensitivity analysis regarding costs of medication

\begin{tabular}{|c|c|c|c|c|c|c|c|}
\hline & $\begin{array}{l}\text { Dexmedetomidine } \\
\text { group }(n=35)\end{array}$ & $\begin{array}{l}\text { Propofol group } \\
(n=34)\end{array}$ & & & & & \\
\hline \multirow[t]{2}{*}{$\begin{array}{l}\text { Costs per } \\
\text { ampoule/flacon }\end{array}$} & $\begin{array}{l}\text { Base case: } € 23.44^{a} \\
\text { Sens } 1: € 22.79^{b}\end{array}$ & $\begin{array}{l}\text { Base case: } € 1.05^{\mathrm{a}} \\
\text { Sens 2: } € 9.56^{\mathrm{b}} \\
\text { Sens 3: } € 36.68^{\mathrm{b}}\end{array}$ & & & & & \\
\hline & Mean (min - max) & SD & Mean (min - max) & SD & $\begin{array}{l}\text { Cost } \\
\text { difference }\end{array}$ & $95 \% \mathrm{Cl}$ & $P$-value \\
\hline
\end{tabular}

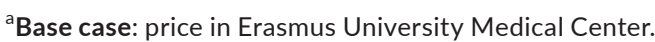

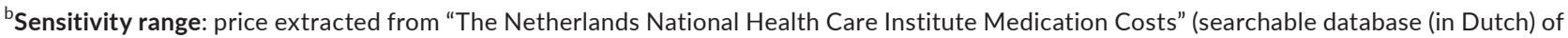
medicine prices (September $2018^{6}$ ), Sens 1: price of the original variant of dexmedetomidine, Sens 2: price of the generic variant of propofol, Sens 3: price of the original variant of propofol, sedative cost $=$ mean costs per the amount of sedative agent used. 
Considering that the mean unit cost of a neurostimulation procedure varied from $€ 5.018,50$ for a trial implant to $€ 22.885,33$ for a definitive implantation, the sedation costs represented only $<0.5 \%$ of the total costs associated with a neurostimulation procedure, both for a trial implant and a definitive implant.

The cost difference between the use of propofol and dexmedetomidine during the implantation of a neurostimulator is statistically significant but factually small. Based on these considerations and on the benefits to the patient when using dexmedetomidine instead of propofol we believe that the choice for dexmedetomidine as a sedative is preferable and justified.

\section{F. F. J. A. ter Bruggen \\ D. L. Stronks \\ F. J. P. M. Huygen}

Department of Anesthesiology, Center for Pain Medicine, Erasmus MC, Rotterdam, The Netherlands

Correspondence

Feline F.J.A. ter Bruggen, Department of Anesthesiology, Center for Pain Medicine, Erasmus MC, Rotterdam, The

Netherlands.
Email: ftbruggen@gmail.com, f.terbruggen@erasmusmc.nl

\section{ORCID}

F. F. J. A. ter Bruggen (iD https://orcid.org/0000-0002-8721-5949

D. L. Stronks (iD https://orcid.org/0000-0002-8463-1285

F. J. P. M. Huygen (iD https://orcid.org/0000-0002-2852-4880

\section{REFERENCES}

1. Ter Bruggen F, Ceuppens C, Leliveld L, Stronks DL, Huygen F. Dexmedetomidine vs propofol as sedation for implantation of neurostimulators: a single-center single-blinded randomized controlled trial. Acta Anaesthesiol Scand. 2019;63(10):1321-1329.

2. Simpson EL, Duenas A, Holmes MW, Papaioannou D, Chilcott J. Spinal cord stimulation for chronic pain of neuropathic or ischaemic origin: systematic review and economic evaluation. Health Technol Assess. 2009;13(17):iii, ix-x, 1-154.

3. Budd K. Spinal cord stimulation: cost-benefit study. Neuromodulation. 2002;5(2):75-78.

4. Elsamadicy AA, Yang S, Sergesketter AR, et al. Prevalence and cost analysis of complex regional pain syndrome (CRPS): a role for neuromodulation. Neuromodulation. 2018;21(5):423-430.

5. Turunen H, Jakob SM, Ruokonen E, et al. Dexmedetomidine versus standard care sedation with propofol or midazolam in intensive care: an economic evaluation. Crit Care. 2015;19:67.

6. Zorginstituut Nederland (Available from: http://www.medicijnko sten.nl.). 